\title{
PRACTICE OF CURRICULUM DESIGN FOR NURTURING GLOBAL COMPETENCY: A CASE STUDY ON COLLABORATION WITH TEACHERS AND PROFESSIONAL EXTERNAL LECTURER
}

\author{
Yoshihisa Nomi ${ }^{1}$ \\ ${ }^{1}$ Akita prefectural board of Education, Akita City
}

\begin{abstract}
In modern society, progress and globalization of science and technology, the change is intense and the future is uncertain. Therefore, it is required to cultivate students who can survive strongly. The aim of this study is school curriculum improvement tried to shift from mastery-type class to competency-type class by utilizing formative assessment. First of all, clarify global competency to be nurtured in the comprehensive lesson "local study (kyodo-gaku)". Teachers and professional external lecturers worked with collaborate on this practical study. To attain this goal, a school based assessment is created with essential question and enduring understanding on the basis of the backward design theory (Understanding by Design framework). Furthermore, Conversation has been done frequently between students, teachers and professional external lecturers during the practice. As a result, Formative assessment was confirmed of effective tool, which might lead to school curriculum improvement. From the questionnaire of post survey, it turned out that students realized their own qualitative ability was improved, through the local study. Behind the scene, to school improvement is done by collegiality (douryousei) and empathy among teachers, which existed as Japanese culture. It is rare that external lecturers actively participate in the curriculum design of high school education, so that this practical study could be a good role model that fosters students in the community.
\end{abstract}

Keywords: - Formative Assessment, Understanding by Design framework, Performance Task, Rubric, Collegiality (Douryousei)

\section{INTRODUCTION}

The structure of society and industry has changed, as we move into a mature society where qualitative richness supports growth, we should not only live in a way that is based on the assumptions of a particular existing organization, but also accept various information and events It is a social imperative to cultivate the power to think how to position oneself in society, to draw society, to live with others, and to solve problems [1].

The development of the science and technology is the one that various conditions consist as a whole, and it is made for the first time. Among them, the enhancement of human resources, such as researchers and engineers, is the nucleus. And such an excellent human resource is not to be formed overnight. It is essential to strive for a steady education from the stage of primary and secondary education. In primary and secondary education, we need to cherish the children's free ideas and nurture rich scientific knowledge such as scientific perspectives and ideas, especially through experiential learning. Therefore, it is necessary to change the keynote to the education which aims at the development of the power which learns voluntarily and thinks voluntarily and creativity from the education which was apt to be taught one-sided knowledge so far. Therefore, students need to be able to find issues, solve problems, disseminate information, and develop their ability to express themselves steadily.
Schools and society share the goal of creating a better society through better schooling in each school, we clarify what kind of educational content we need to learn, and what qualities and abilities we can acquire. We need to achieve that through cooperation and collaboration with society. In order to practice the curriculum open to society, it is required to promote the use of local educational resources [2].

\section{AIM OF THIS REASERCH.ABOUT RESEARCH SCHOOL}

Goshono Gakuin High School (hereinafter, a research school) is implementing local study program (kyodo-gaku), the integrated studies about homeland in Akita, JAPAN.

\section{What is Local Study Program in research school?}

This program aims to develop the students' ability to have broad views for society and the world, and to think of ways to solve problems they find around them. It started as a part of the curriculum of the "Period for Integrated Studies." Through this program, students are expected to learn globally, express themselves, and take actions on their own in our home Akita as their base of learning.

Through the "Basic Program" in the first year, students gain a broad knowledge about our home Akita regarding history, 
nature, economy, medical and welfare services by professional lectures. In the second year, they choose a course from "Globalization and Akita", "Regional vitalization and Economy", "Environment and Human", and "Health and Food". They learn more specifically in their chosen field through lectures by professionals and selfexperience such as fieldwork. With deeper research and understanding, they decide on their own research topic, and propose a solution in the form of presentations. In the final year, students choose their own themes according to their future careers, and write a research paper.

Fig-1 shows a conceptual diagram visualizing the general educational activities in research schools. Students are at the center of educational systems. It is surrounded by the skills necessary to survive society of the future, and the curriculum necessary for that. Furthermore, it shows that various external resources such as nature, culture, climate, region, and etc. support school education.

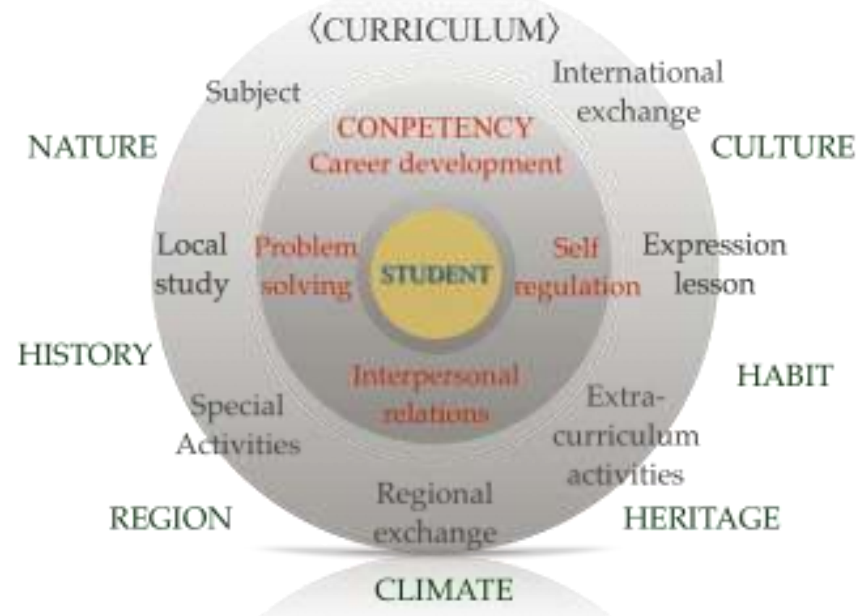

Fig-1: Conceptual diagram visualizing the general educational activities in research schools

\section{METHODOLOGY}

The aim of this research is to design a curriculum focusing on competency development. Project period: 2016 to 2018. Since competency is one of difficult academic skills, it is necessary to devise a way beyond the conventional evaluation method to grasp how students assemble knowledge / thinking.

In this research, we focused on formative assessment, which makes use of teacher's guidance and learners' learning improvement [3], [4]. Formative assessment is an interactive assessment that measures the student's academic achievement progress and comprehension level, making it possible to judge learning needs accurately and improve the lesson approach more appropriately. Furthermore, feedback also leads to enhance in self-adjustment ability on students' learning [5]. First, clarify the skills that students wish to acquire, and share them with all staff.Next, plan and design the learning contents and assessment necessary for that purpose. In addition, "backward design theory" was used as an assessment tool to visualize the learning and guidance [6].As a research summary over three years, we examine the effectiveness of contents of the curriculum, assessment tools, formative assessment and the UbD templates from interviews and questionnaire surveys for students, teachers and external lecturers.

\subsection{Assessment Tool}

To clarify the ability to nurture, to refer to the backward design in order to design learning about the flow of guidance, the setting and evaluation of tasks [6]. It is decided various evidences and tasks from students obtained through learning as proof of formative assessment and to make use of coordination of instruction and learning.

\section{PRACTICE}

\subsection{Efforts to Improvement}

First, we conducted questionnaires for improving local study for all teachers and external lecturers. Table-1 shows a part of its contents.

Table-1: Questionnaire for teachers and external lecturers

- We leave all the contents to an external lecturer. Teachers need to be actively involved more and more.

- I think we do not share what kind of ability to acquire for students, between instructors and teachers.

- It is necessary to contrive to continue the contents of the first year and the contents of the second year.

- It is necessary to make contents of $1 \mathrm{st}, 2$ nd year learning useful in research paper of 3 rd year.

Based on the results of this questionnaire, it has formulated an improvement plan as follows.

A) Teachers and external lecturers through repeated discussions to set up the abilities* to nurture for students.

B) Improve content-based lecture to competency-based lecture.

C) It is set performance issues that are aware of essential question and enduring understanding.

D) It will be conducted a questionnaire survey in order to grasp the effect of this study.

*The global competency is defined as ability to "Problem Solving", "Interpersonal Relations", " Self-Regulation, and "Career Development".

\subsection{First Year and Performance Task}

The "Basic Program" in the first year, students gains a broad knowledge about our home Akita regarding history, nature, economy, medical and welfare services by professional lectures. Course by external lecturer ( 7 times a year, once 
each 100 minutes). In advance, discuss the contents of the lecture and the aims between external lecturers and teachers

(Table-2). On the worksheet, write the theme, related keywords, and point of attendance and use rubric, which clarified the required goal. The performance task is a summary report of each course.Also, conduct peer assessment between students about those reports.In addition, cultivate system thinking through work that connects and keywords learned in each course (3 times a year, once each 100 minutes).

Table-2: Ability to acquire and performance task of First year in Basic program.

Ability to acquire:
Motivation and attitude to receive lecture. Ability to
summarize in your own words. Ability to tell others
easily.
Performance task:
Each summary report (weekend task). Peer assessment.
Collaborate on related charts.

\subsection{Second Year and Performance Task}

In the second year, they choose a course from "Globalization and Akita", "Regional vitalization and Economy", "Environment and Human", and "Health and Food". They learn more specifically in their chosen field through lectures by professionals and self-experience such as fieldwork. With deeper research and understanding, they decide on their own research topic, and propose a solution in the form of presentations. When creating an annual instruction plan, we shared the ability to nurture through lectures among external lecturers and teachers in charge, and repeated discussions and discussed on necessary lectures and experiences for that purpose. Reports and preparation of reports on experience experiences in each course were regarded as performance task. Created posters as performance task. In order to unify teaching methods among teachers who are in charge of two year local studies, essential question and enduring understanding were set for each course based on the backward reverse design theory ( Table-3). In addition, we developed our own UbD template at the summary of local studies (It is omitted posting of templates in this paper). The UbD template is not a one-shot lesson plan, but it is a mid- to long-term learning plan for the whole unit. We will clarify the intention of each learning and share direction and direction of guidance. Furthermore, formation evaluation along the time series became possible, and the state of change of the student was able to be collected more effectively. As a tool for clarifying student learning direction, "Rubric for presentation" was developed.

"ENVIRONMENT AND HUMAN " Course [Ability to
acquire] We consider environmental problems as our
own problems, practice from familiar things and propose
improvement methods. To acquire the ability to actively
participate in regional revitalization. [Essential question]
Draw a future image, what do we do from now on?
[Enduring understanding] Understanding the essence of

environmental problems from the relationship between

Akita's water environment problem and local Lake.

"GLOBALIZATION AND AKITA " Course [Ability to acquire $]$ In a time when diverse values are required; we have a global perspective and have flexible thinking. [Essential question] What are the differences in values and thoughts about internationalized society? [Enduring understanding] Understand the connection between Akita and the world, such as exchange with foreign countries, economic cooperation.

Table-3: Course study program in second year "HEALTH AND FOOD " Course[Ability to acquire] Learn scientific knowledge and skills about food and cultivate the ability and attitude to be able to practice a healthy and fulfilling life. Provide accurate food information and safe and secure food environment. We will propose solutions to problems related to meals. [Essential question] How have traditional food and local food and food culture been established? [Enduring understanding] Understand the relationship between population decline and regional economy.

"REGIONAL VITALIZATIONAND ECONOMY Course[Ability to acquire] Although it is closely related to us, we can explain to ourselves economy, which is invisible to the eye.[Essential question] What can be done for regional revitalization?[Enduring understanding] Understand nutrients and their functions.

\subsection{Third Year and Performance Task}

In the final year, students choose their own themes according to their future careers, and write a research paper. Under the guidance of the teacher in charge, work on preparing the paper while declaring / confirming the progress situation. Performance task is Writing research paper about 9,000 letters. Teachers exchanges information so that there is no difference in guidance among the teachers in charge and instructs based on developed "research papers rubric" (in this paper, we omit posting). It is conducted ingroup presentation sessions, conducted peer assessment among students, set scenes where advice from others was feedback to the work. A good work set scenes to be shown at the "Research Paper Releasing Session". It is try to foster Information collecting ability, ability to think things in many ways and logically innovation.

\section{DISCUSSION}

It is considered the effectiveness of curriculum design and method from interview and questionnaire survey by students, teachers and external lecturers (Table-4 to 7).

Table-4: External lecturer's impressions

- Many students made preparations and began to attend lectures ambitiously.

- I have taken charge of lectures for many years, 
Lecture attitude is improving a lots.

- By setting up a reflection scene that each students summarizes the lecture and tells it to others in an easy-to-understand manner, it has helped foster the foundation for considering common content in multiple viewpoints.

Table-5: The student's impressions after finishing the second year local study.

\section{(1)Peer assessment}

- It is good to know the improvement point, which I did not notice.

- It leads to improvement, as you can understand your actions seen by others。

(2) What you feel from descriptive word evaluation from others (free description)

- It is a little hesitant to write your own improvement points. But opinions from others can be obedient.

- Although it was aware of comments, I pointed out that I firmly pointed out that it was good.

Table-6: A part of the students' impressions after the third year local study.

- I understand the goodness of the area where I live.

- I got the ability to find and explore tasks on my own.

- I was able to have a problem consciousness to the problem which is happening in Japan, the world, mastery of knowledge.

- I became able to look at the world and have interest. It gave me a chance to make me realize where my interests are oriented. It has become possible to grasp things in many ways.

Table-7: Teacher's impressions.

\section{About guidance incorporating formative assessment}

(A) Effect on students side

- Evaluation from a friend became a stimulus, motivation improved each time, and the presentation was also trying hard.

- Students were easy to work as they aimed for; the required forces were clearly indicated.

(B) Effect on teaching side

- Since I do not have to instruct unilaterally, I was able to evaluate without reducing my burden.

- Considering the connection with subjects, it seems to be possible to consider the evaluation items from the perspective from each subject in the same way as the essay task.

By accepting analysis and criticism from peers through peer assessment, the ability to objectively see things develops, which can also be used for self-assessment [3],[7].

Similar results were obtained in this study. This practical study was conducted for 3 years from 2016 to 2018. Fig-2 shows the results of a follow-up survey of self-evaluation results on the global competency ("Problem Solving", "Interpersonal Relations", "Self-Regulation, "Career
Development") of 56 students who were in the first year of the research in high school in 2016. Students themselves also realize that these capabilities are improving. It is believed that formative assessment has been effective in coordinating teaching and learning.

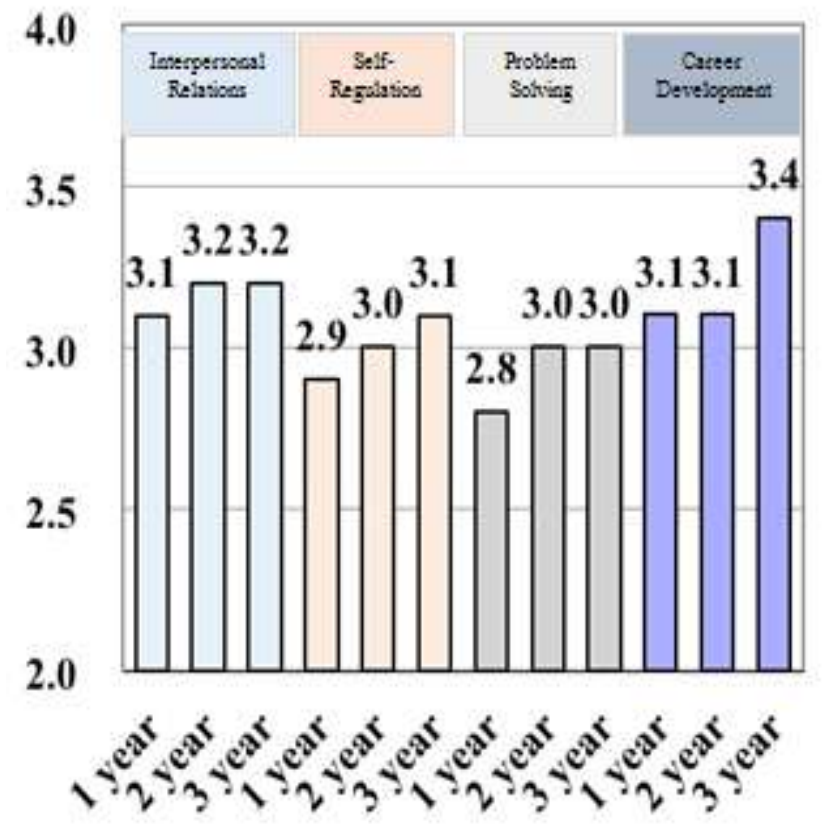

Fig-2: Results of self-evaluation about the competency

\section{CONCLUSION}

Formative assessment based on feedback that has the core of this research is the key to assessment among students, and it is a prerequisite that mutual evaluation is done accurately. Therefore, by introducing activity to assess based on rubric, which clarified the criteria, it was able to obtain certain effect. There are challenges though. For example, if student have knowledge about a theme properly, they can make an accurate assessment on the contents, and advice after writing to others will be more effective. It is necessary to develop assessment tools to develop competencies based on the stage, such as ability to assess basic knowledge and skills, assessment with various perspectives; self-adjustment ability demonstrating meta-cognition is there.

In this research, we clarified the qualities and abilities to be trained through the local study and tried to understand teachers and students in common. Furthermore, we developed a unique UbD template of the school, whichclarified "essential question" and "enduring understanding", and tackled "improvement of learning quality" using formative assessment method. Students' motivation for learning improved by conducting peer assessment in various situations and instantly feeding students the results. Students always try to improve their learning while referring to the criteria and think that the improvement of the qualities and abilities that aimed at as a result was seen. 
Behind the scene, to school improvement is done by collegiality (douryousei) and empathy among teachers, which existed as Japanese culture. In order to solve the problem all the faculty shared the problem consciousness, worked on improving the curriculum with high collegiality, accelerated research promotion and made a big leap forward. It is required to train global human resources who can be active in international society, diversity and cooperation. The subject "local study" is a curriculum consisting of uniquely rich content with the theme of local folk Akita. It is aimed to nurture the global perspective by thinking things on a global scale through community-based activities and nurturing human resources who are active globally. It is believed that the curriculum has been improved to support the qualities and abilities supported by the learning content by incorporating formative assessment. Various exploratory activities are being carried out at each high school. It is thought that the method of curriculum development that incorporates the viewpoint of assessment by cooperation and collaboration between the faculty and the external lecturer in this research may be a model of emphasizing competency development.Collegiality (douryousei)

\section{ACKNOWLEDGMENT}

Tohoku University Graduate School of Education Graduate School Professor Masahiro Arimoto gave me guidance and advice in detail about the formative assessment method and the method of curriculum development in detail.

\section{REFERENCES}

[1]. MEXT (2016). Improvement of the course of study of kindergarten, elementary school, junior high school, high schools and special support schools, etc., and necessary measures (report). Central Education Council. 2016.12.21

[2]. MEXT (2007). The idea of new course of study-from discussion in the Central Educational Council to revision and implementation.

[3]. Sadler, R. (1989). Formative assessment and the design of instructional systems. Instructional Science, 18, 119-144.

[4]. Yamamoto, S., (2013). A Study of Feedback as Formative Assessment: Analysis on Royce Sadler's theories. Annual Bulletin, Graduate Scholl of Education, Tohoku University Vol.61 (23). 113-127.

[5]. CERI. (2005). Formative assessment: ImprovingLearning in secondary classrooms. Paris:OECD.

[6]. G. Wiggins and J. McTighe. (2005). Understanding by Design, Expanded 2ndEdition. Alexandria, VA: Association for Supervision and Curriculum Development ASCD.

[7]. Black, P. Harrison, C., Lee, C., Marshall, B. \&William, D. (2003). Assessment for learning: putting it into practice. Maidenhead: Open University Press. [9] OECD. (2005). 'Formative Assessment: Improving Learning in Secondary Classrooms'. Policy Brief November 2005.

\section{BIOGRAPHIES}

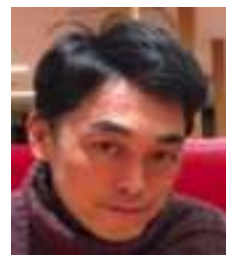

Yoshihisa nomi: Educational Supervisor. Akita prefectural board of Education, Akita City, 